\title{
Bimbingan Teknis Pembuatan dan Penulisan Inovasi Pelayanan Publik Bidang Pendidikan Tahun 2021
}

\author{
Yohanes Susanto $^{1}$, R.A. Zubaidah ${ }^{2}$ \\ ${ }^{1}$ Program Magister Manajemen Universitas Bina Insan Lubuklingau \\ ${ }^{2}$ STIE Trisna Negara Blitang Oku Selatan \\ Email: ${ }^{1}$ Susantoyohanes60@gmail.com. ${ }^{2}$ ra.zubaida_kag@yahoo.com
}

\begin{abstract}
The purpose of this study is to explain the performance of junior high school teachers in the city of palembang, the innovation revolution in the development of public services in schools. This study used a quantitative approach and descriptive data as well as quantitative data by using several questions or questionnaires to respondents or technical guidance participants. Quantitative data was obtained through questionnaires with intervals. The results showed that the participants of the technical guidance of public service innovations were very good, it was proven that there was an increase in the value of the results of the $t$ test, pre-test scores and $t$-test scores post $=$ test, there was an increase of $37.64 \%$, this indicates a fairly good absorption of guidance participants technical. This assessment becomes a reference in implementing teachers in an effort to improve public service innovation in schools. It is recommended to the organizers of the education office of Palembang City in the future that there is a need for technical training on strategic management of teacher innovation in utilizing the potential of the school environment they have for the development of knowledge and skills of their students.
\end{abstract}

Keywords: Public Service Innovation, Junior High School, Assessment Model

\section{Abstrak}

Tujuan Peneitian ini adalah untuk menjelaskan kinerja guru SMP di kota palembang revolusi Inovasi dalam pegembagan pelayanan publik di sekolah. Dalam penelitian ini digunakan pendekatan kuantitatif dan data deskriptif serta data kuantitatif dengan mengunakan beberapa pertanyaan atau kuisioner kepada serponden atau peserta bimbingan teknis dat kuantitatif diperoleh memalui kuisioner dengan interval. Hasil penelitian menunjukan bahwa para peserta bimbingan teknis inovasi pelayanan publik sangat baik, terbukti adanya peningkatan nilai dari hasil uji t nilai pre-tes dan uji t nilai pos-tes ada peningkatan sebesar 37,64 \% ini menunjukan adanya penyerapan yang cukup baik dari peserta bimbinan teknis. Penilaian ini menjadi acuan dalam mengimplementasikan para guru dalam upaya meningkatkan inivasi pelayanan publik di sekolah. Disarankan kepada pihak peneyelenggra dinas pendidikan Kota Palembang kedepan perlu adanyanya diklat teknis manajemen startegis inovasi guru dalam memanfaatkan potensi lingkungan sekolah yang dimiliki untuk pegembangan ilmu dan keterampilan anka didiknya.

Kata Kunci: Inovasi Pelayanan Publik, SMP, Model Penilaian.

\section{A. PENDAHULUAN}

Semakin hari tuntutan perkembangan teknologi semakin besar tatkala menyebabkan sistem pendidikan kini bergeser dari konvensional menuju ke modern. Terlebih pada era Industri 4.0 ditambah pandemi Covid-19 saat ini menuntut adanya inovasi dalam teknik belajar mengajar. Seperti yang diketahui bahwa saat ini kegiatan belajar mengajar tidak terikat oleh ruang dan waktu. Adanya kemajuan perangkat teknologi menyebabkan guru dan murid saat ini tidak perlu bertatap muka dalam menjalankan kegiatan pendidikan. Dengan kata lain dalam pelayanan publik pada bidang pendidikan sedikit demi sedikit sudah menerapkan sistem $e$ government. Namun, alih-alih me mpermudah layanan pendidikan ternyata fungsi guru tetaplah penting. Bagi orangtua yang memiliki kesibukan akan menjadi masalah dalam proses belajar anak di rumah. Kemudian, bagi daerah yang memiliki akses teknologi yang terbatas seperti di pedalaman, sistem belajar daring sangatlah tidak tepat. Dengan kata lain, sebagai pengajar, guru masih harus ke setiap rumah murid untuk mengajar. Sebagai contoh guru di Toba, 
Sumatera Utara dan di Kabupaten Mamasa, Sulawesi Barat yang harus ke rumah-rumah siswa demi mengajar dan antar jemput tugas pelajaran karena keterbatasan fasilitas dan jaringan internet. Hal tersebut menunjukkan bahwa sehebat apapun kecanggihan teknologi, namun jasa guru tidak akan pernah tergantikan. Selain sebagai pendidik dalam hal akademis, akan tetapi guru juga memiliki peranan penting dalam mendidik moral siswa/i nya. Hal inilah yang seringkali terlupakan padahal dampaknya sangat besar bagi kematangan emosional dan pembentukan moralitas bangsa. Budaya ketimuran Indonesia yang lebih menekankan tata krama dan sopan santun tidak lepas dari adanya peran guru sebagai pendidik. Pada masa pandemi saat ini sudah tentu hal tersebut menjadi tantangan tersendiri. Ternyata, kemajuan teknologi dan perkembangan layanan pendidikan tidak secara mentah dapat diterima. Tetap saja, peran guru sangatlah penting dalam pembentukan moral dan tidak dapat tergantikan oleh apapun. Oleh karena itu, pelayanan publik dalam bidang pendidikan memiliki urgensitas karena berdampak terhadap berbagai aspek kehidupanBerdasarkan Pasal 4 Undang-Undang Nomor 20 Tahun 2003 Tentang Sistem Pendidikan Nasional terkait prinsip penyelenggaraan pendidikan bahwa pendidikan diselenggarakan secara demokratis dan berkeadilan serta tidak diskriminiatif. Selain itu pendidikan dimaknai dalam memberikan keteladanan, membangun kemauan, dan mengembangkan kreativitas peserta didik dalam proses pembelajaran Oleh karena itu, dalam rangka mewujudkan pelayanan dan pengawasan bidang pendidikan yang prima diperlukan kerja sama antar berbagai pemangku kepentingan terlebih pada masa pandemi Covid-19. Hal tersebut sesuai dengan hak dan kewajiban penyelenggara maupun penerima layanan publik yang dalam Undang-Undang Nomor 25 Tahun 2009 tentang Pelayanan Publik. Adapun aktivitas pengawasan pendidikan ditujukan bukan untuk mencari-cari kesalahan, melainkan dalam rangka pelaksanaan fungsi manajemen untuk mencapai mutu pendidikan yang berkualitas. Sebagaimana dikemukakan oleh Robbin dan De Censo (2001) bahwa fungsi pengawasan dilakukan untuk mencapai tujuan organisasi, yaitu planning, organizing, leading and controlling. Pengawasan juga dilakukan dengan tujuan agar pelaksanaan tugas pokok organisasi agar berjalan secara efektif dan efisien sesuai peraturan perundang-undangan yang berlaku. Pengawasan dalam bidang pendidikan dibagi menjadi tiga, yaitu pengawasan fungsional (dilakukan oleh Inspektorat dan pihak internal), pengawasan teknis (dilakukan oleh BPK dan BPKP termasuk Ombudsman RI atau pihak eksternal), dan pengawasan masyarakat. Mengingat urgensitas pengawasan dalam pelayanan pendidikan diharapkan nantinya kualitas pendidikan semakin baik termasuk juga pada peningkatan kesejahteraan guru.dari hasil telaah terhadap pelayanan publik di bidang pendidikan sudah baik menurut hasil penelitian Sinaga.M.S at all (2020) hasil penelitian Ahmad Syamsir (2017) bahwa siatem pembelajaran dimasa covid 19 dengan menggunakan during e-goverment dapat meningkatkan pelayanan publik sektor pendidikan, pendidik/guru harus memastikan kegiatan belajar mengajar tetap berjalan meskipun peserta dididk berada dirumah, inovasi pembelajaran merupakan solusiyang perlu didesain dan diaksankan oleh para guru dengan memaksimalkan media yang ada seperti media daring (online) guru dapat melakukan pembelajaran meggunakan metode e-learning yaitu informasi dan komunikasi, sistem pembeajaran diaksanakan melalui perangkat komputer (PC)atau Laptop yang terhubungan jaringan internet, guru dapat melakukan pembelajaran bersama diwaktu yang sama menggunakan grup di media sosial seperti Whatsapp (WA) telegram, aplikasi Zoom ataupun media sosial lainnya sebagai sarana pembelajaran sehingga dapat memastikan siswa belajar diwaktu bersamaan meskipun siswa belajar berbeda. Guru juga dapat memberikan tugas terukur namun tetap memastikan bahwa tiap hari pembelajaran peserta didik terlaksana tahap demi tahap dari tugas tersebut, banyak lagi inovasi lainnya yang bisa dilakuka oleh pendidik demi memastikan pembelajaran tetap berjalan dan siswa mendaatka imu sesuai dengan kurikulum yang teah ditetapkan pemerintah. Kepala Sekolah juga harus berinovasi dalam menjalankan fungsi supervisi atau pembinaan kepada Guru untuk memastikan bahwa kegiatan belajar mengajar telah dilakukan oleh guru dan peserta didik meskipun menggunakan metode jarak jauh (daring). Kepala Sekolah juga dapat memberikan solusi dan motivasi kepada guru di sekolah, sehingga guru-guru yang belum siap memanfaatkan media daring dapat disupervisi dan diberi solusi. Untuk pengawas sekolah dibawah naungan Dinas Pendidikan Provinsi maupun Kota dan Kabupaten juga dapat berinovasi agar tetap menjalankan pengawasan dan tujuan dari supervisinya dapat berjalan dengan baik meskipun tidak harus selalu bertatap muka.

\section{B. PELAKSAAAN DAN METODE}

\section{a) Metodologi Pelaksanaan}

Tempat dan waktu. Bimbingan Teknis Pembuatan dan penulisan Inovasi Pelayanan Publik bidang pendidikan pelaksanaan di Hotel Fave Kota Palembang Jln. R Soekamto Kec Kemuning Kota Palembang Sumatera selatan 30151

Khalayak sasaran. khalayak sasaran pada kegiatan ini adalah para Guru-guru kelas tingakt Sekolah Menegah Pertama, SMP se-Koata Palembang sebanyak 100 orang guru

Metode Pengabdian. Kegiatan yang dilakukan pada pengabdian ini adalah pemberian materi manajemen 
pelayanan publik bidang pelayanan pendidikan memberikan pengetahuan dan pemahaman pada guru-guru terhadap kewajiaban dan hak-haknya sebagai pendidik dan pelayanan masyarakat dengan menggunakan metode ceramah, praktek, dan diskusi. Tingkat pemahaman materi dievaluasi menggunakan kuesioner yang dikerjakan sebelum dan sesuda

Pemberian materi. Menurut hasil peneitian (Roiful Wahyudi at all 2019) metode dengan menggunakan kombinas

klasifikasi dengan menerapkan metode ceramah, diskusi dan role play, hasil pelatihan menunjukan bahwa adanya peningkatan pemahaman terhadap aspek yang di bahas

Indikator Keberhasilan. Indikator keberhasilan kegiatan ini berdasarkan hasil evaluasi pemahaman terhadap meteri yang diberikan, menunjukkan terdapat perbedaan pengetahuan minimal $25 \%$ pada pegawas koperasi setelah mengikutinya.

Metode Evaluasi. Metode evaluasi pada kegaiatan ini menggunakan kuosioner yang diberikan sebelum (pre) dan setelah (post) pelatihan. Kuesioner meliputi dua bagian: yang pertama berisi pertanyaan tentang identitas responden, sementara yang kedua berisi 20 pertanyaan tertutup mengenai pemahaman dan pengetahuan kewajiban pendidik dalam melaksanakan pelayanan publik Program ini berjalan selama satu (1) hari dengan tiga (3) kali kelompok materi pembelajaran oleh Guru-guru SMP di Kota palembang

\section{b) Pelaksanaan Kegiatan}

Kegiatan pengabdian ini resmi dibuka oleh kepala dinas Peididikan Nasional Kota Palebang Sumatera selatan H. Ahmad Julinto.S.Pd.M.M Sebelum masuk ke sesi materi setiap peserta dilakukan perkenalan diri masing-masing yang gunanya untuk mengetahui latar belakang tugas pokok guru yang bersangkutan, kemudian kepada para peserta diminta untuk mengisi kuesioner yang telah disiapkan pemateri untuk mengetahui pegetahuan awal para peserta dimaksud. Kedudukan guru sebagai pendidik sangat penting dan starategis, guru adalah perwakilan orang tua murid dalam melakukan pengawasan terhadap pendidikan anak di sekolah, guru memiliki fungsi kontrol dan pengendalian agar anak tetap terarah dan berjalan pada koridor yang telah disepakati agar senantiasa taat pada koridor jati diri sebagai siswa didik dan setiap semester guru wajib melaporkan tugasnya pada Kepala sekolahnya.rutinitas kegiata inovasi pelayanan publik bagi setiap guru wajib dilaksanakan oleh setiap guru, keadaan dunia dan pandemik yang melanda memaksakan setiap guru harus mampu berinoasi dalam upaya melaksanakan tugas pokok dan fungsinya sebagai tenaga pendidik.

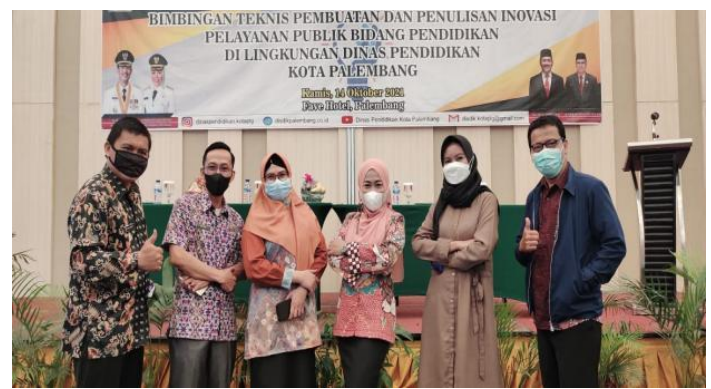

Gambar 1. Peserta Bimbingan Teknis

Jenis data yang didapatkan adalah data primer yaitu berasal dari kegiatan langsung serta wawancara langsung dari peserta bimbingan. Kegiatan berjalan dengan pembelajaran dengan materi terbagi tiga sesion yaitu ; Konsep dan prinsip pelyanan publik, Pola fikir Aparatus sipil negara sebagai pelayanan publik, Pratik etikat pelayanan publik, sebelum masuk pemberian materi terlebih dahulu dilakukan pre-tes pada semua peserta untuk mengukura kedalamnan pengetahuan para peserta bimbinan teknis dimaksud.

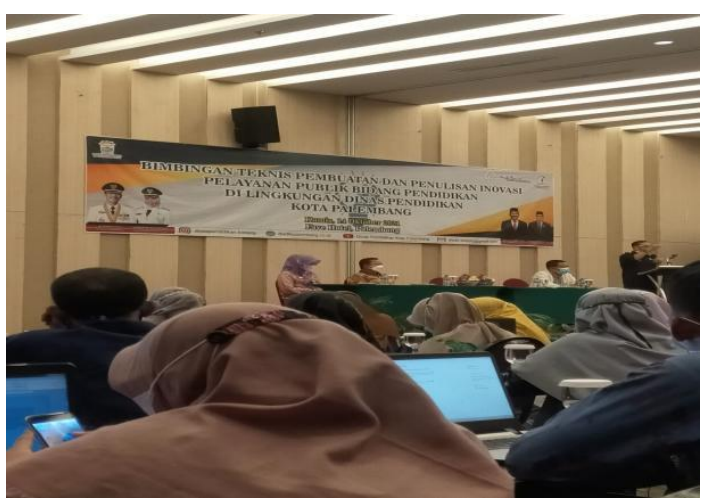

Gambar 2. Pelaksanaan Pre-tes

\section{HASIL DAN PEMBAHASAN}

\section{a) Pembekalan Materi}

Mutu yang baik merupakan dambaan setiap orang, terlebih dalam bidang pendidikan. Mutu pendidikan biasanya terdiri dari beberapa indikator dan komponen yang saling barkait. Komponen dan variabel yang menetukan terwujudnya mutu pendidikan yang baik secara umum, masih dikaitkan dengan sistem, kurikulum, tenaga pendidik, peserta didik, PBM, anggaran, sarana dan prasarana pendidikan, lingkungan belajar, budaya organisasi, kepemimpinan dan lain sebagainya (Onisimus, 2010: 138). Mutu pendidikan tidak dilihat dari hasil UN dan hasil test belajar siswa. Mutu adalah serangkaian proses sampai dengan outpun, dan outcome. Dalam konteks pendidikan kualitas dapat diartikan sebagai kemampuan sekolah dalam pengelolaan secara operasional dan efisien terhadap komponenkomponen yang berkaitan dengan sekolah, sehingga menghasilkan nilai tambah terhadap komponen 
tersebut menurut norma/standar yang berlaku. Sekolah berkualitas adalah sekolah yang mampu mewujudkan siswa-siswa yang bermutu, yang sesuai dengan tujuan pendidikan yaitu manusia yang cerdas, terampil, dan berbudi pekerti luhur, bertaqwa kepada Tuhan Yang Maha Esa, serta memiliki kepribadian yang baik.

Sekolah berkualitas sangat erat hubungannya dengan pemberian layanan pendidikan yang bermutu, dan untuk mengetahui tingkat ketercapaian kualitas itu, maka sekolah berkualitas harus merujuk kepada PP No. 19 Tahun 2005 tentang Standat Nasional Pendidikan di Indonesia meliputi : 1) standar isi, 2) standar kompetensi lulusan, 3) standar proses, 4) standar sarana dan prasarana, 5). Standar pengelolaan, 6). Standar pendidik dan tenaga kependidikan, 7) standar

pembiayaan, dan 8) standar penilaian (Depdiknas, 2006). Dari ke-8 standar itu kemudian akan dapat ditentukan apakah sekolah itu berkualitas dan bermutu, walaupun mutu bukan satu-satunya diukur dari ke-8 standar tersebut. Tercapainya kualitas dari kedelapan standar itu kemudian berujung kepada layanan pendidikan kepada peserta didik dan masyarakat serta stakeholder pendidikan sebagai bagian dari konsumen atau customer pendidikan.

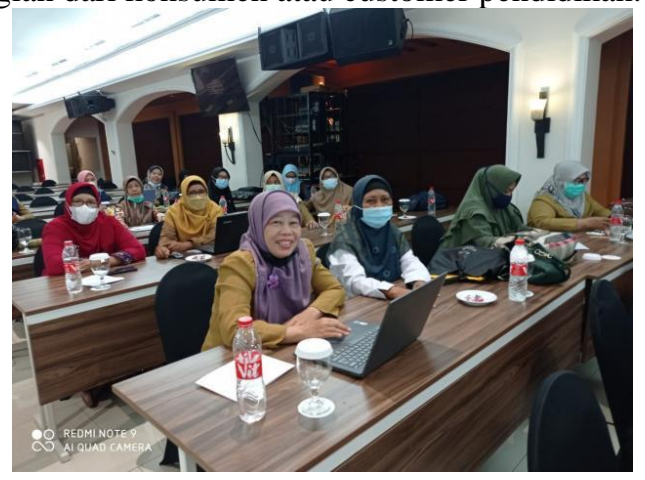

Gambar 3. Pelaksanaan Bimbinan Teknis
Sekolah sebagai institusi pendidikan, memiliki karakteristik sekolah berkualitas dan sekolah bermutu, sebagai alat ukur sederhana tercapainya mutu pendidikan dapat dilihat dari pelaksanaan operasi Manajemen Mutu Terpadu (MMT) atau Total Quality Management (TQM) yang dilaksanakan dalam pendidikan. Menurut Sallis (2010), dengan indikator sebagai berikut :Terjadinya perbaikan yang terus meneru, Perubahan kultur, Organisasi terbalik, Menjaga hubungan dengan pelanggan, Kolega sebagai pelanggan, Pemasaran internal, Profesionalisme dan fokus pelanggan, dan Mutu pembelajaran.

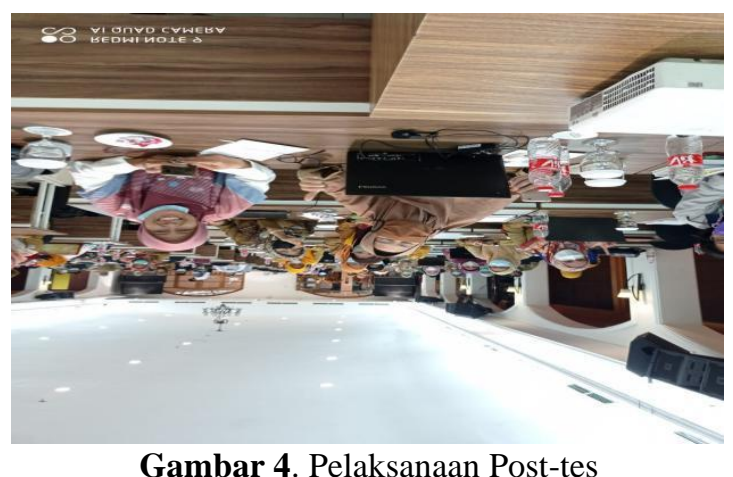

b) Keberhasilan Kegiatan

Hasil Pengisisn kuiesioner dari masing-masing peserta bimbingan teknis inovasi pelayanan publik untuk para guru, dengan uji kelayakan diambil sampel 15 orang.

Hasil pegisian kuesioner dari masin-masing peserta bimbingan teknis sebelum dan sesudah mendapatkan materi tujuannya untuk mengentahui seberapa besar keberhasilan dalam pelaksanaan kegiatan bimbingan tekis dimaksud. Lalu diolah uji t berpasangan (tabel 1) dibawah.

Tabel 1. Hasil penilaian pemberain materi Inovasi Pelayanan Publik

\begin{tabular}{|c|c|c|c|c|}
\hline Peserta & Nilai Pre-test & Nilai Post-test & \multicolumn{2}{|c|}{ Perbedaan } \\
\hline $\mathrm{n}$ & $\mathrm{y} 1$ & $\mathrm{y} 2$ & $\mathrm{D}$ & $\mathrm{D}^{2}$ \\
\hline 1 & 55 & 60 & 5 & 25 \\
\hline 2 & 50 & 55 & 5 & 25 \\
\hline 3 & 53 & 60 & 7 & 49 \\
\hline 4 & 60 & 62 & 2 & 4 \\
\hline 5 & 60 & 65 & 3 & 9 \\
\hline 6 & 56 & 60 & 4 & 16 \\
\hline 7 & 58 & 60 & 2 & 100 \\
\hline 8 & 60 & 70 & 10 & 121 \\
\hline 9 & 44 & 55 & 11 & 225 \\
\hline 10 & 45 & 60 & 15 & 144 \\
\hline 11 & 48 & 60 & 12 & 81 \\
\hline 12 & 53 & 62 & 9 & 16 \\
\hline 13 & 56 & 60 & 4 & 100 \\
\hline 14 & 60 & 64 & 4 & 10 \\
\hline 15 & 55 & 65 & & \\
\hline
\end{tabular}




\begin{tabular}{|c|c|c|c|c|}
\hline Jumlah & 813 & 1.119 & 94 & 935 \\
\hline $\bar{y}$ & 54,20 & 74,60 & & \\
\hline
\end{tabular}

Perhitungan t- hitung

$$
\begin{aligned}
\mathrm{S}^{2} \mathrm{D} & =\left\{\left(\Sigma \mathrm{D}^{2}-(\Sigma \mathrm{D})^{2} / \mathrm{n}(\mathrm{n}-1)\right.\right. \\
& =\left(935-(94)^{2} / 15(15-1)=(935-8.836) / 14=506,50\right. \\
\mathrm{S} \quad & =\sqrt{ } \mathrm{S}^{2} \mathrm{D} / \mathrm{n}=\sqrt{506,50 / 15}=\sqrt{33}, 77=5,81 \\
\mathrm{t}-\mathrm{hit} & =\left(\overline{\mathrm{y}}_{1}-\overline{\mathrm{y}}_{2}\right) / \mathrm{S}=(54,20-74,60) / 5,81=-3,511
\end{aligned}
$$

Setelah perhitungan t-hitung, dibandingkan dengan $\mathrm{t}$ - tabel pada kolom (n-1) pada baris ke 14 pada kolom dengan $\alpha 0,05$ tampak nilai t- tabel sebesar 2,145. karena nilai t-hitung $=3,511$ dan nilai $\mathrm{t}$-tabel 2,145, dimana nilai pre-test berbeda dengan nilai post-tes dan rata-rata nilai post-test lebih besar dari nilai pre-test. Maka, bisa disimpulkan bahwa metode pembelajaran yang diberikan pada para guru secara konkret mampu menambah pemahaman dan pengetahuan atas materi yang disampaikan pemateri. Utamanya, para guru memahami kewajiban dan hakhaknya sebagai pendidik. Menurut (Marzuki 2012) ada enam strategi indikator keberhasilan pelatihan meliputi strategi akdemik, strategi laboratorium, strategi aktivitas action, strategi pegembangan perseorangan dan strategi pengembangan orgaisasi. Menurut (Notoadmojo, 2015) pelatihan di katakan berhasil apabila terjadi proses tranformasi dalam hal adanya indikasi meningkatnya kemampuan dalam menjalankan tugas serta perubahan perilaku yang ditunjukkan dalam etos kerja, disiplin dan hasil kerja. Menurut (As'ad, 2014), keberhasilan pelatihan dapat dilihat dari lima kriteria: sasaran pelatihan yang jelas, bisa diuraikan dalam perilaku yang dapat di ukur dan diamati, pelatih diharuskan mampu mengajarkan atau menyampaikan materinya dengan metode yang tepat sehingga peserta akhirnya mendapatkan ilmu, kecakapan serta sikap yang dibutuhkan sesuai dengan target yang ditetapkan, materi pelatihan harus dibuat sesuai dengan target pelatihan, metode dan media pelatihan perlu dirangkai secara akurat, peserta yang aktif merupakan hal yang penting dalam keberhasilan pelatih.

\section{PENUTUP}

\section{a) Kesimpulan}

Bahwa pelaksanaan pengabdian ini khususnya dalam pembinaan para Guru sekolah mengenh pertama SMP se-Kota palembang sangat bermanfaat terbukti dari hasil pre-tes dan post-tes peserta menunjukan hasil yang signifikan faktor pendukungnya adalah sarana dan fasilitas pelaksanaan kegiatan di tanggung pihak penyelenggara dan faktor penghambat adalah tidak semua peserta memiliki latar belakang manjemen Sumber daya Manusia jadi sedikit sulit dalam memahami pengembangan inovasi pelayanan publik.

Disarankan agar kegiatan kedepan Dinas Pendidikan Kota palembang Sumatera selatan dapat menyediakan materi atau topik pelatihan pada para guru khusus mengkaji Manajemen strategi pemberdayaan siswa sehingga para guru akan lebih memahami peluang inovasi pembelajaran yang harus diterapkan dengan fokus terhadap inovasi lingkungan sekolah atau regiaonal yang dimiliki daerah sehingga para anak didik bisa memanfaatkan peluang belajar yang akhirnya dapat bersaing merebut kesempatan sekolah lanjutan berikutnya.

\section{b) Ucapan Terima Kasih}

Penulis mengucapkan terimaksih kepada dinas Pendidikan Kota palembang Sumatera selatan yang telah bersedia mengikut sertakan penulis sebagai narasumber dalam kegiatan pelatihan pada para Guru SMP di Kota Palembang, Sumatera selatan.

\section{E. DAFTAR PUSTAKA}

As'ad, Moh. 2013. Psikologi Industri, Seri Ilmu Sumber Daya Manusia, Liberty, Jakarta

Ahmad.S. MIchsan Noor, Idah.W.Siti.A. (2019)Kualitas pelayanan publik dalam pembelajaran berbasis during di tengah pandemik covid 19, Kualitas Libery UIN Sunan Gunung Djati Bandung. https://core.ac.uk/download/pdf/327164541.p df

De.Cenzo,David A., 2011 Stephen P. Robbins. Human Resource Management,

Concept and Practices, Jhon Wiley and Sons, Inc., Fourth edition, USA,

Roiful. W, Riduan. Ahmad.A (2019)Pelatihan pengawas koperasi syariah bersertifikasi di daerah Yogyakarta, jurnal Abdimas Universitas Admad Dahlan Vo 3 No 3

Marzuki, Saleh. H.M. (2012). Pendidikan Nonformal. Dimensi dalam Keaksaraan 
Fungsional, Pelatihan, dan Andragogi. kepuasan layanan pendidikan, Jurnal Bandung: Penerbit Rosda. Administrasi Pelaynan Publik Vol 8 No 2

Notoatmodjo, Soekidjo, (2015) Pengembangan Sumber Daya Manusia, Jakarta: Rineka Cipta,

Undang-Undang No 20 Tahun 2003 tentang sistem pendidikan Nasional

Sallis. 2010. Manajemen Mutu Terpadu. Bogor: IRCiSoD

Undang-Undang Nomor 25 Tahun 2009 Tentang Pelayanan Publik

Sinaga.M.S, Aji Suraji.M.(2020) Melalui survei kepuasan Masyarakat terhadap tingkat

Peraturan Pemerintah No 19 Tahun 2001 tentang standard Pendidikan Nasional. 